\title{
First records of the sole, Aseraggodes kobensis (Steindachner, 1896) (Pleuronectiformes, Soleidae), from Malaysia
}

\author{
Jo Okamoto ${ }^{1}$, Siti Tafzilmeriam Sheikh Abdul Kadir ${ }^{2}$, Hiroyuki Motomura ${ }^{3}$, Tun Nurul Aimi Mat \\ Jaafar $^{4}$, Ying Giat Seah ${ }^{2,4}$
}

1 Faculty of Fisheries, Kagoshima University, 4-50-20 Shimoarata, Kagoshima 890-0065, Japan. 2 South China Sea Repository and Reference Centre, Institute Oceanography and Environment, Universiti Malaysia Terengganu, 21030, Kuala Nerus, Terengganu, Malaysia. 3 The Kagoshima University Museum, 1-21-30 Korimoto, Kagoshima 890-0065, Japan. 4 Faculty of Fisheries and Food Science, Universiti Malaysia Terengganu, 21030 Kuala Nerus, Terengganu, Malaysia.

Corresponding author: Ying Giat Seah, ygseah@umt.edu.my

\begin{abstract}
Fifteen specimens (56.4-112.9 mm standard length) of Aseraggodes kobensis (Steindachner, 1896) were collected from Malaysia. This species was previously known from southern Japan to the Gulf of Thailand and western India, and the new records expand its range south in the Western Pacific by about $750 \mathrm{~km}$. A detailed description is given for the specimens, the first collected from Malaysian waters.
\end{abstract}

\section{Keywords}

Biogeography, distribution, demersal fish, marine fish, range extension, South China Sea.

Academic editor: Hudson Tercio Pinheiro | Received 1 July 2019 | Accepted 12 October 2019 | Published 15 November 2019

Citation: Okamoto J, Sheikh Abdul Kadir ST, Motomura H, Mat Jaafar TNA, Seah YG (2019) First records of the sole, Aseraggodes kobensis (Steindachner, 1896) (Pleuronectiformes, Soleidae), from Malaysia. Check List 15 (6): 991-995. https://doi.org/10.15560/15.6.991

\section{Introduction}

The Soleidae is the largest family in Pleuronectiformes and has 183 valid species (Fricke et al. 2019) in 32 genera (Froese and Pauly 2019). These fishes are known as "ikan lidah" in Malaysia, where there are 17 species in 10 genera (Annie and Albert 2009; Ambak et al. 2012; Froese and Pauly 2019). The genus Aseraggodes Kaup, 1858 , which is the most species-rich soleid genus with 53 valid species (Munroe 2001; Randall et al. 2013), is characterized by the following combination of characters: snout without a distinct hook, mouth slightly contorted, caudal fin separated from dorsal and anal fins, dorsaland anal-fin bases without pores, and pectoral fins absent (Munroe 2001; Randall and Bartsch 2005).
During fieldwork near Pulau Bidong, Terengganu in 2015, specimens of an unidentified sole were collected. Subsequently, additional specimens of the same species were collected by us from fish landing ports at Chendering (Kuala Terengganu) and Tok Bali (Kelantan). Specimens were collected from bottom trawlers, which is the prime fishing gear in Malaysia (Seah et al. 2016). The specimens are identified here as Aseraggodes kobensis (Steindachner, 1896), a species previously known from Japan and the Philippines to Chantha Buri, northern Gulf of Thailand and western India (Imamura 2013; Nair and Gopalakrishnan 2013). Accordingly, the present specimens represent the first records from Malaysia and southernmost records for the species. Aseraggodes 
kobensis joins A. senoui Randall \& Desoutter-Meniger, 2007 as only the second species of Aseraggodes collected from Mabul Island, Sabah, Malaysia.

\section{Methods}

All fish catches were sorted in accordance with the standard protocol by Sparre and Venema (1998), and the procedures for fixation, photography, and preservation of specimens followed Seah et al. (2011). Methods for counting and measuring generally followed Hubbs and Lagler (2004), and the terminology of morphological features and descriptions were modified from Randall et al. (2013). Specimens were measured to the nearest 0.1 $\mathrm{mm}$ using digital calipers (Mitutoyo, Japan); the abbreviation $\mathrm{SL}=$ standard length, $\mathrm{HL}=$ head length. Species identifications followed Nakabo (2002), Imamura (2013), and Jeong (2017). All specimens were deposited in the South China Sea Repository and Reference Center, Universiti Malaysia Terengganu, Malaysia (UMTF).

\section{Results}

Class Actinopterygii

Order Pleuronectiformes

Family Soleidae

Genus Aseraggodes Kaup, 1858

\section{Aseraggodes kobensis (Steindachner, 1896)}

Figure 1

New records (Fig. 2). Malaysia - Terengganu: Pulau Bidong $\left(05^{\circ} 39^{\prime} 12.79^{\prime \prime} \mathrm{N}, 103^{\circ} 06^{\prime} 47.57^{\prime \prime} \mathrm{E}-05^{\circ} 35^{\prime} 32.89^{\prime \prime} \mathrm{N}\right.$, $103^{\circ} 08^{\prime} 2.86^{\prime \prime}$ ), T.N.A. Mat Jaafar and Y.G. Seah

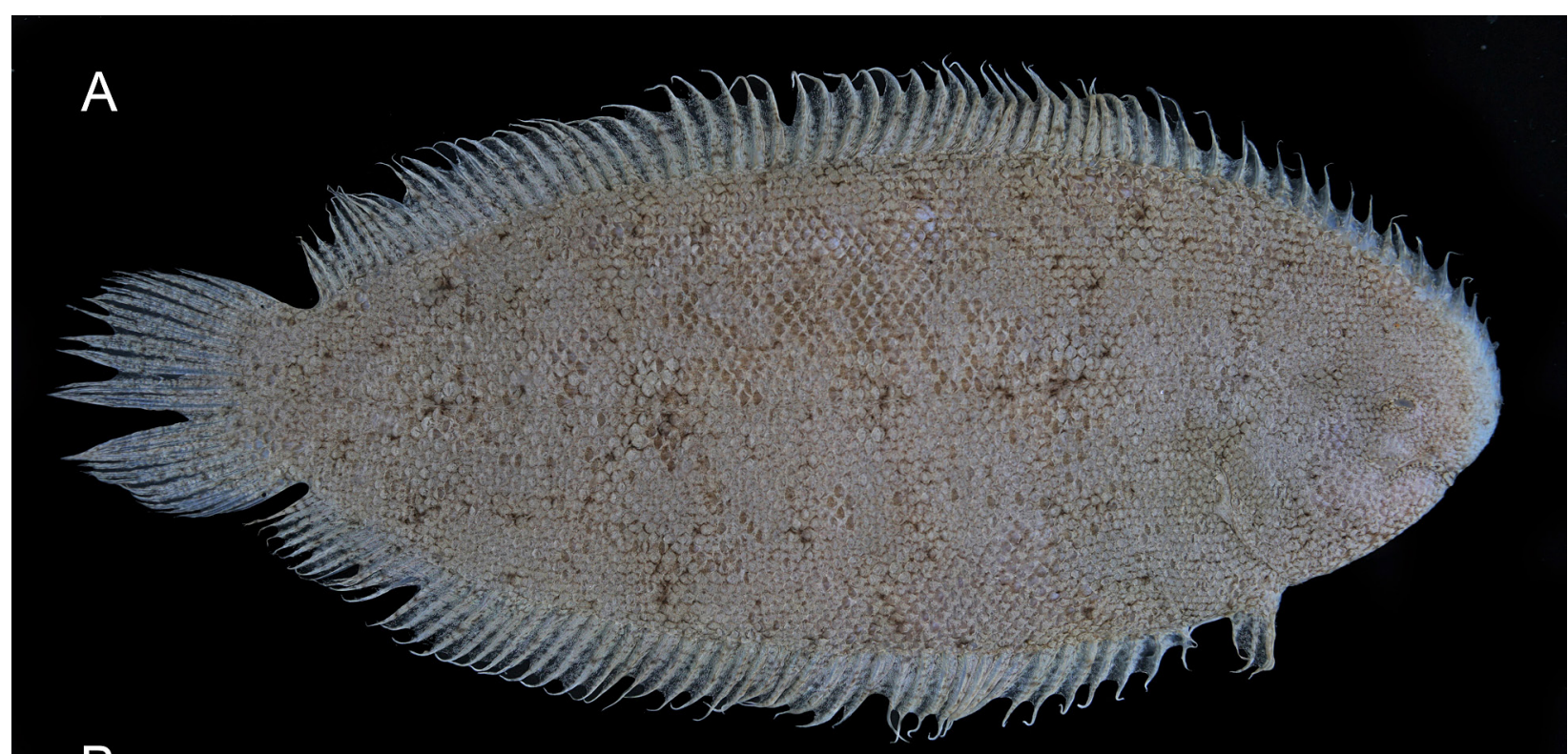

B

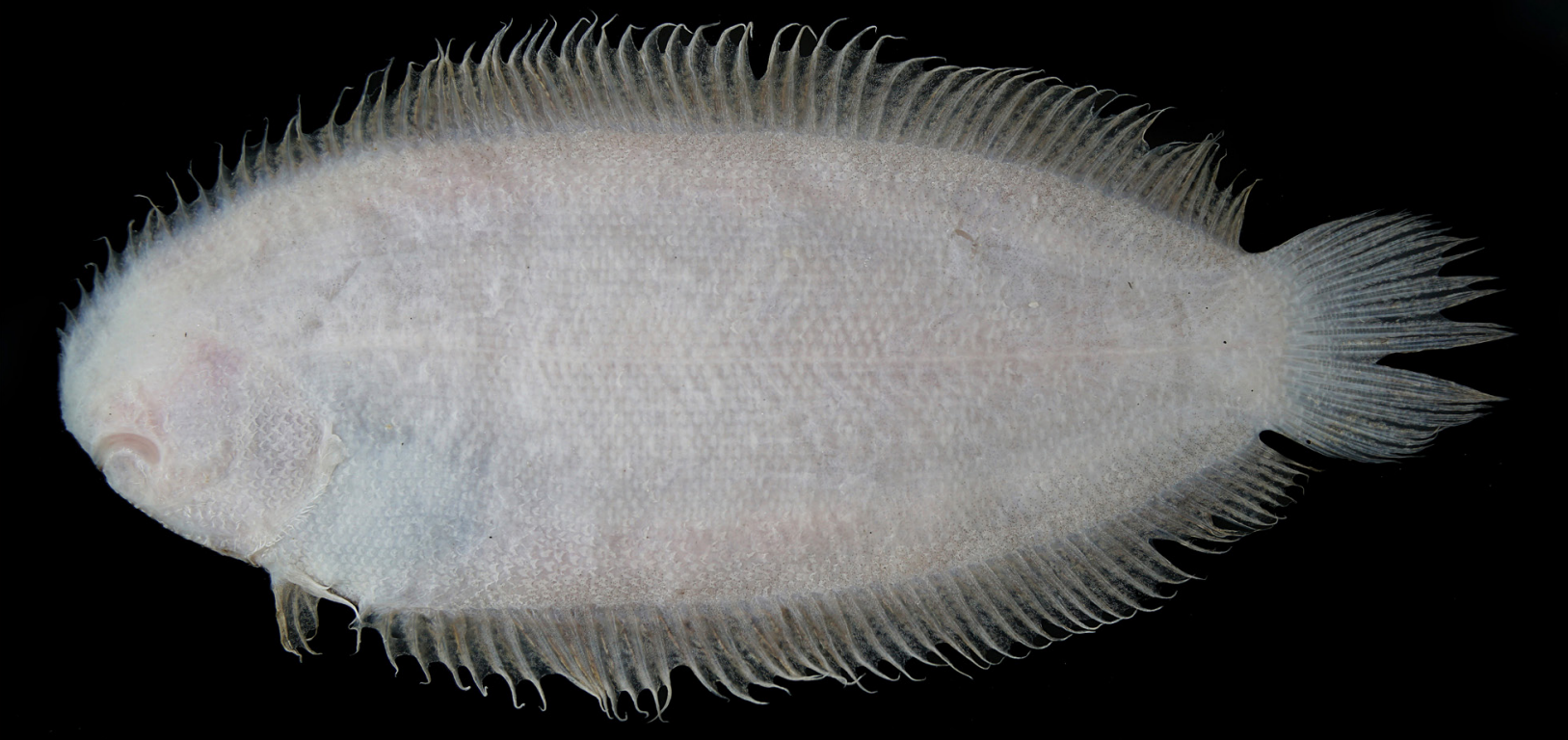

Figure 1. Fresh specimen of Aseraggodes kobensis (UMTF 8502, $82.0 \mathrm{~mm} \mathrm{SL)} \mathrm{A.} \mathrm{Ocular} \mathrm{side.} \mathrm{B.} \mathrm{Blind} \mathrm{side.}$ 
collectors, 9 Sept. 2015, 4 spec. (UMTF 6457, $74.3 \mathrm{~mm}$ SL; UMTF 6460, 112.9 mm SL; UMTF 6652, $69.6 \mathrm{~mm}$ SL; UMTF 6453, $69.3 \mathrm{~mm}$ SL). • Terengganu: Chendering fish landing port $\left(05^{\circ} 15^{\prime} 51.31^{\prime \prime} \mathrm{N}, 103^{\circ} 11^{\prime} 07.08^{\prime \prime} \mathrm{E}\right)$, S.T. Sheikh Abdul Kadir and J. Okamoto collectors, 2 Oct. 2018, 7 spec. (UMTF 8500, 56.4 mm SL; UMTF 8501, $85.6 \mathrm{~mm}$ SL; UMTF 8506, $74.4 \mathrm{~mm}$ SL; UMTF 8507, $69.0 \mathrm{~mm}$ SL; UMTF 8508, $68.7 \mathrm{~mm}$ SL; UMTF 8509, 71.9 mm SL; UMTF 8510, 77.6 mm SL). Kelantan: Tok Bali fish landing port $\left(05^{\circ} 53^{\prime} 22.49^{\prime \prime} \mathrm{N}, 102^{\circ} 28^{\prime} 22.05^{\prime \prime} \mathrm{E}\right)$, S.T. Sheikh Abdul Kadir and J. Okamoto collectors, 10 Oct. 2018, 4 spec. (UMTF 8502, 82.0 mm SL; UMTF 8503, $70.1 \mathrm{~mm}$ SL; UMTF 8504, $94.7 \mathrm{~mm}$ SL; UMTF $8505,64.1 \mathrm{~mm} \mathrm{SL})$.

Identification. Counts and measurements are given in Table 1. A fresh specimen (UMTF 8502) is shown in Figure 1. The specimens collected from Malaysia were identified from the following combination of characters, which closely match the diagnostic features given by Nakabo (2002), Imamura (2013), and Jeong (2017) for A. kobensis: body moderately elongate; mouth small and slightly contorted; bases of dorsal and anal fins without pores; pectoral fin absent on both sides; pelvic fin on ocular side slightly longer than that on blind side, close together and not joined to anal fin; anterior nasal tube short, not reaching to lower eye anterior margin on ocular side; caudal fin not connected to dorsal and anal fins; body uniformly pale brown with some faint dark brown blotches on ocular side, uniformly white on blind side; dorsal and anal fins uniformly brownish when fresh.

Description. Body moderately elongate; ventral profile of head posterior to mouth slightly convex; medial of upper eye in front of the anterior of lower eye; horizontal level of upper end of gill opening about one orbit diameter below lower eye, the ocular side end slightly curved, with a scaleless membrane, and tubular in some individuals; caudal peduncle present, posteriormost dorsal and anal fins ray separated from base of caudal fin ray; jaws weakly curved; maxilla extending slightly posterior to anterior edge of lower eye; blind side of upper and lower jaws with a narrow band of close-set villiform teeth; anterior nostril on ocular side not reaching lower eye when nostril laid backward, its length less than eye diameter; no cirri on edge of gill opening on either side; eyes not protruding, cover without scales; scales strongly ctenoid on ocular and blind sides, extending broadly onto medial and anterior parts of eyes; front of snout and chin on blind side without low fleshy papillae; lateral line straight on

Table 1. Counts and measurements of Aseraggodes kobensis. Abbreviations: $G B=$ Marine Biodiversity Referral Museum of Central Marine Fisheries Research Institution, Kochi, India. $\mathrm{O}=$ Ocular side, $\mathrm{B}=$ Blind side, $\mathrm{U}=$ Upper eye, $\mathrm{L}=$ Lower eye.

\begin{tabular}{|c|c|c|c|c|}
\hline & \multicolumn{2}{|c|}{$\begin{array}{c}\text { This study } \\
\text { Non-types (Malaysia) } \\
n=15\end{array}$} & \multicolumn{2}{|c|}{$\begin{array}{c}\text { Nair and Gopalakrishnan (2013) } \\
\text { Non-type (western Indian Ocean) } \\
\text { GB.33.14.3.12 } \\
n=1\end{array}$} \\
\hline Standard length (mm) & \multicolumn{2}{|c|}{$56.4-112.9(76.0)$} & \multicolumn{2}{|c|}{76.2} \\
\hline \multicolumn{5}{|l|}{ Counts } \\
\hline Dorsal fin rays & \multicolumn{2}{|c|}{$69-76(72)$} & \multicolumn{2}{|c|}{67} \\
\hline Anal-fin rays & \multicolumn{2}{|c|}{$49-54(52)$} & \multicolumn{2}{|c|}{48} \\
\hline Pelvic fin rays (O) & \multicolumn{2}{|c|}{5} & \multicolumn{2}{|c|}{5} \\
\hline Pelvic fin rays (B) & \multicolumn{2}{|c|}{$4-6(5)$} & \multicolumn{2}{|c|}{5} \\
\hline Caudal fin rays $(\mathrm{O} / \mathrm{B})$ & \multicolumn{2}{|c|}{$18(2+14+2)$} & \multicolumn{2}{|c|}{$18(2+14+2)$} \\
\hline Lateral line scales $(\mathrm{O})$ & \multicolumn{2}{|c|}{$67-75(71)$} & \multicolumn{2}{|c|}{-} \\
\hline Measurements & (as \% SL) & (as \% HL) & (as \% SL) & (as \% HL) \\
\hline Body depth & $34.1-39.1(41.8)$ & - & 39.5 & - \\
\hline Body width & $7.5-9.0(8.8)$ & - & - & - \\
\hline Head length & $16.8-23.5(21.7)$ & - & 28.3 & - \\
\hline Preorbital length & $5.7-7.9(7.2)$ & $26.8-38.3(33.0)$ & - & - \\
\hline Snout length (U) & $4.9-6.9(6.4)$ & $22.5-33.3(28.4)$ & 6.8 & 24.0 \\
\hline Eye diameter (U) & $2.4-3.0(3.0)$ & $11.5-15.4(13.4)$ & 3.9 & 13.8 \\
\hline Eye diameter (L) & $2.3-3.0(3.0)$ & $11.1-15.4(13.1)$ & 3.9 & 13.8 \\
\hline Interorbital width & $1.2-2.0(1.9)$ & $5.3-13.0(8.4)$ & 3.4 & 12.0 \\
\hline Upper-jaw length & $5.5-7.9(6.7)$ & $27.2-34.3(30.6)$ & 9.1 & 32.1 \\
\hline Caudal peduncle length & $10.6-16.6(13.0)$ & $50.0-70.6(58.5)$ & 12.3 & - \\
\hline Pre-anal fin length & $23.1-29.6(26.8)$ & $110.4-137.5$ (122.6) & 36.3 & - \\
\hline Pre-pelvic fin length & $16.8-20.6(18.8)$ & $74.9-93.9(85.7)$ & 28.5 & - \\
\hline First dorsal ray length & $1.6-6.0(3.0)$ & $7.1-25.5(13.0)$ & - & - \\
\hline Longest dorsal ray length & $8.5-14.8(11.6)$ & $40.9-63.0(52.3)$ & 8.8 & - \\
\hline First anal ray length & $3.2-4.3(4.2)$ & $15.2-24.3(19.3)$ & - & - \\
\hline Longest anal ray length & $9.6-14.1(11.4)$ & $43.9-60.0(52.3)$ & 9.4 & - \\
\hline Caudal fin length & $16.9-20.7(20.5)$ & 84.4-105.3 (94.8) & 18.3 & - \\
\hline Pelvic fin length $(\mathrm{O})$ & $6.9-9.2(8.2)$ & $32.0-41.1(37.8)$ & 9.2 & - \\
\hline Pelvic fin length (B) & $4.8-9.2(6.8)$ & $22.2-39.1(31.7)$ & 7.3 & - \\
\hline
\end{tabular}




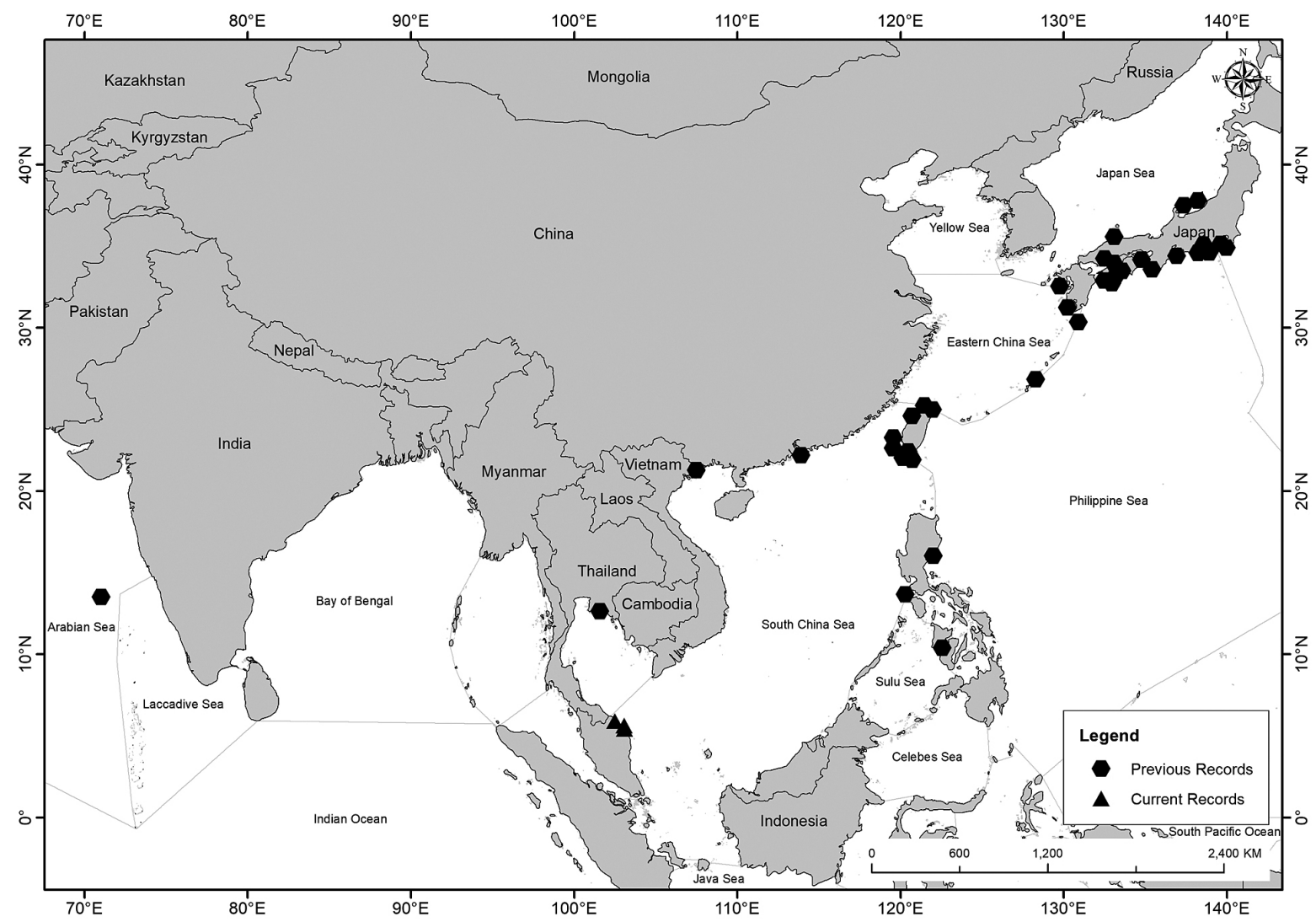

Figure 2. Map of Indo-West Pacific Ocean showing records of Aseraggodes kobensis. Black hexagons = previous records. Black triangles = new Malaysian records.

both sides of body, ending on ocular side about one eye diameter posterior to upper eye; scales not extending onto dorsal and anal fins on either side; scales present on caudal fin base; origin of dorsal fin anterior to upper eye; first anal fin ray level with base of 19th to 21st dorsal fin ray; caudal fin strongly rounded; pelvic fins adjacent on ventral margin of body, the ocular-side fin a little anterior; second and third pelvic fin rays longest, reaching base of second anal fin ray; anus anterodorsal and adjacent to first anal ray. When fresh (Fig. 1), on ocular side body pale brown with scattered darker brown speckles, on blind side generally pale or rarely whitish with an obscure brown tinge adjacent to dorsal and anal fins; scales on ocular side narrowly edged with dark brown; fin rays paler brown than body; membranes translucent.

\section{Discussion}

Aseraggodes kobensis was originally described by Steindachner (1896), as Solea (Achirus) kobensis, based on a mature specimen collected from Kobe, Hyogo Prefecture, Japan. Ochiai (1984) referred the species to Aseraggodes, with which it shares common features with other Aseraggodes species. Although A. kobensis is most similar to Aseraggodes umbratilis (Alcock 1894), known from the Indian Ocean, the latter differs from A. kobensis in having smaller eyes, no cirri on the front of the snout, a longer caudal peduncle, and a shorter caudal fin (Nair and Gopalakrishnan 2013).
Aseraggodes kobensis has previously been recorded from the northwestern Pacific Ocean from Japan to the northern Gulf of Thailand, including Taiwan, Hong Kong, Vietnam, and the Philippines, and from the western Indian Ocean (Imamura 2013; Nair and Gopalakrishnan 2013; Jong 2017; Fricke et al. 2019). The presence of $A$. kobensis in Malaysia was expected, and our new records narrow the gap of its distribution in the IndoWest Pacific Ocean. Indeed, Aseraggodes kobensis is common off the east coast of Peninsular Malaysia, where it is mainly caught by bottom trawler together with species of Leiognathidae, Bothidae, and crustaceans. However, A. kobensis is not found in local markets; its small size makes it unmarketable, and thus it is processed into fertilizer. In Malaysia, untargeted fish species often receive relatively little attention compare with commercial fishes in ichthyological studies, make the marine fishes remain poorly known (Mat Jaafar et al. 2019; Seah et al. 2016). Aseraggodes kobensis is a small species and Imamura (2018) recorded a maximum standard length of $10.0 \mathrm{~cm}$. However, UMTF 6460 (112.9 mm SL) is now the largest known specimen of this species. The Malaysian specimens represent the southernmost records of $A$. kobensis in the South China Sea.

\section{Acknowledgements}

We are grateful to staff of the South China Sea Repository and Reference Center, Universiti Malaysia Terengganu 
for their support during Jo Okamoto's internship at the university. Special thanks go to Mohd Rodila bin Ibrahim for his assistance during Jo Okamoto's stay and the fish survey. G. Hardy (Ngunguru, New Zealand) checked the English manuscript. Jo Okamoto gratefully acknowledges a "Tobitate! Young ambassador program" scholarship provided by Ministry of Education, Culture, Sports, Science and Technology, Japan. Y.G. Seah thanks the School of Fisheries and Aquaculture Sciences for maintaining an annual ichthyofaunal survey and Yuzwan bin Mohamad for generating the distribution map. This study was supported in part by the Kagoshima University projects "Establishment of Research and Education Network on Biodiversity and Its Conservation in the Satsunan Islands" (adopted by the Ministry of Education, Culture, Sports, Science and Technology, Japan) and "Island Research" (to H. Motomura).

\section{Authors' Contributions}

YGS and TNAMJ designed the plan. YGS, TNAMJ and HM identified the species. JO and STSAK collected data. JO edited the photographs of the specimens. JO wrote the manuscript and made the measurements. All authors reviewed, finalized, and approved the manuscript.

\section{References}

Ambak MA, Isa MM, Zakaria MZ, Ghaffar MA (2012) Fishes of Malaysia. Second edition. Penerbit Universiti Malaysia Terengganu, Kuala Terengganu, Terengganu, $x i+301$ pp.

Annie PKL, Albert CG (2009) Field guide to marine \& estuarine fishes of Sarawak. Fisheries Research Institute Bintawa, Kuching, Sarawak, iii + 316pp.

Fricke R, Eschmeyer WN, Van der Laan R (Eds) (2019) Eschmeyer's catalog of fishes: genera, species, references. http:// researcharchive.calacademy.org/research/ichthyology/catalog/ fishcatmain.asp. Accessed on: 2019-3-3.

Froese R, Pauly D (Eds) (2019) FishBase, version 04/2019. http:// www.fishbase.org. Accessed on: 2019-9-25.

Hubbs CL, Lagler KF (2004) Fishes of the Great Lakes region (Revised edition by Smith GR). University of Michigan Press, Ann Harbor, Michigan, USA, xvii + 332 pp.

Imamura H (2013) Soleidae (Soles). In: Yoshida T, Motomura H, Musikasinthorn P, Matsuura K (Eds) Fishes of northern Gulf of Thailand. National Museum of Nature and Science, Tsukuba, Research Institute for Humanity and Nature, Kyoto, and Kagoshima University Museum, Kagoshima, 217-220.
Imamura H (2018) Soleidae (Soles). In: Kimura, S., H. Imamura, V. Q. Nguyen and T. D. Pham (Eds) Fishes of Ha Long Bay, the natural world heritage site in northern Vietnam. Fisheries Research Laboratory, Mie University, Shima, Japan, 294-298.

Jeong B (2017) Soleidae. In: Motomura H, Alama UB, Muto N, Babaran RP, Ishikawa $\mathrm{S}$ (Eds) Commercial and bycatch market fishes of Panay Island, Republic of the Philippines. Kagoshima University Museum, Kagoshima, University of the Philippines Visayas, Iloilo, and Research Institute for Humanity and Nature, Kyoto, Japan, 222-226.

Mat Jaafar TNA, Lee JN, Mazlan AG, Sheikh Abdul Kadir ST, Seah YG (2019) Opistognathus nigromarginatus Rüppell, 1830 (Perciformes, Opistognathidae), Bridled Jawfsh: a frst record from Malaysia. Check List 15 (5): 883-886. https://doi.org/ $10.15560 / 15.5 .883$

Munroe TA (2001) Soleidae (Soles). In: Carpenter KE, Niem VH (Eds) FAO species identification guide for fishery purposes. The living marine resources of Western Central Pacific. Volume 6. Bony fishes part 4 (Labridae to Latimeriidae), estuarine crocodiles, sea turtles, sea snakes and marine mammals. FAO, Rome, 3878-3889.

Nakabo T (2002) Soleidae (soles). In: Nakabo T (Ed.) Fishes of Japan with pictorial keys to the species, English edition. Tokai University Press, Tokyo, Japan, 1383-1387.

Nair RJ, Gopalakrishnan A (2013) Milk sole fish Aseraggodes kobensis (Pleuronectiformes: Soleidae) - a new record from the Western Indian Ocean. Indian Journal of Geo-Marine Sciences 42 (2):174-176

Ochiai A (1984) Soleidae. In: Masuda H, Amaoka K, Araga C, Uyeno $\mathrm{T}$, Yoshino $\mathrm{T}$ (Eds) The fishes of the Japanese archipelago. Tokai University Press, Tokyo, 354-355

Randall JE, Bartsch P (2005) Two new soleid fishes of the genus Aseraggodes from Micronesia, with a record of $A$. smithi from Palau. Micronesica 38 (1):125-139.

Randall JE, Bogorodsky SV, Mal AO (2013) Four new soles (Pleuronectiformes: Soleidae) of the genus Aseraggodes from the western Indian Ocean. Journal of the Ocean Science Foundation 8: $1-17$.

Seah YG, Chua YN, Sam CW, Teoh HY (2016) Length-weight relationships of seven fish species from a fish landing port at Sungai Udang, Penang, Malaysia. Journal of Applied Ichthyology 32 (6): 1353-1355. https://doi.org/10.1111/jai.13216

Seah YG, Mazlan AG, Abdullah S, Zaidi CC, Usup G, Mohamed CAR (2011) Feeding guild of the dominant trawl species in the southeastern waters of Peninsular Malaysia. Journal Biological Sciences 11 (2): 221-225. https://doi.org/10.3923/jbs.2011.221.225

Sparre P, Venema SC (1998) Introduction to tropical fish stock assessment, part 1: manual (FAO Fisheries Technical Paper No. 306/1 Rev. 2). FAO, Rome, Italy, 422 pp.

Steindachner F (1896) Bericht über die während der Reise Sr. Maj. Schiff "Aurora" von Dr. C. Ritter v. Microszewski in den Jahren 1895 und 1896, gesammelten Fische. Annalen des Naturhistorischen Museums in Wien 11: 197-230. 